To reference this article please use the following citation:

Williams, C., Sandall, J., Lewando-Hundt, G., Heyman, B., Spencer, K. and Grellier, R. (2005). Women as moral pioneers? Experiences of first trimester antenatal screening. Social Science \& Medicine. Vol. 61, No. 9, pp. 1983-1992. 


\section{Women as moral pioneers? Experiences of first trimester antenatal screening}

Authors: Clare Williams, Jane Sandall, Gillian Lewando-Hundt, Bob Heyman, Kevin Spencer and Rachel Grellier

\section{Abstract}

The implementation of innovative medical technologies can raise unprecedented ethical, legal and social dilemmas. This is particularly so in the area of antenatal screening, which is dominated by the language of risk and probabilities. Second trimester serum screening for Down's syndrome and neural tube defects has a well-established place in antenatal care. Increasingly, first trimester screening with biochemical and ultrasound markers is being proposed as advance on this, yielding higher detection rates of Down's syndrome at an earlier gestational age. This article explores the experiences of 14 women offered innovative first trimester screening, which takes place within the context of a detailed ultrasound scan. The study is set within the UK, where recent policy changes mean that the offer of screening for fetal anomalies, particularly Down's syndrome, will become a routine part of antenatal care and offered to all pregnant women.

This paper focuses on the significance of the scan in first trimester screening, and some of the potential dilemmas for women that can result from this. It then discusses the ways in which women made their decisions about screening, in particular, their work as 'moral pioneers'. We found that the part played by the ultrasound scan in first trimester screening, particularly in relation to the higher-quality images now being obtained, has the potential to introduce new and novel ethical dilemmas for pregnant women. Although concerns have been raised about pregnant women viewing ultrasound scans as benign, many of the women reported having thought carefully through their own moral beliefs and values prior to screening. It seems that whatever other implications they may have, first trimester screening technologies will continue the tradition of pregnant women acting as 'moral pioneers' in increasingly complex settings.

Keywords: UK, First trimester antenatal screening, Innovative health technologies, Down's syndrome, Patient experience.

\section{Introduction}

The implementation of innovative medical technologies (IMTs) can raise unprecedented ethical, legal and social dilemmas, particularly in the linked specialties of obstetrics and fetal medicine (Getz \& Kirkengen, 2003). More generally, Fox (2000, p. 422) believes that recent advances in biomedicine and medical technologies lie at the heart of the uncertainty underpinning the recent Western development of bioethics:

...US bioethics implicitly deals with uncertainty-fraught questions of value, belief, and meaning that are as religious and metaphysical as they are medical and moral. What is life? What is death? When does a life begin? When does it end? What is a person? What is a child?... Is it better not to have been born at all than to have been born with a severe genetic defect? How vigorously should we 
intervene in the human condition to repair and improve ourselves? And when should we cease and desist?

Such uncertainty also manifests itself in the forms of classifications and diagnoses that IMTs generate, particularly in the area of genetics. As Webster (2002, p. 447) argues, these are, 'more likely to depend on the language of risk and probabilities than the language of causality'. One major area where risk language predominates is that of antenatal care, specifically antenatal screening. Rapp's (1999) seminal work in this area highlights many of the dilemmas that pregnant women currently face within the predominant Western biomedical model of pregnancy, where choices and decisions are often based on uncertainty. She states:

... came to think of the women who submitted to the discipline of a new reproductive technology in order to reap its biomedical benefits as moral pioneers. At once conscripts to techno-scientific regimes of quality control and normalisation, and explorers of the ethical territory its presence produces, contemporary pregnant women have become our moral philosophers of the private (1999, p. 306).

However, Rapp's work was based on traditional 2nd trimester antenatal screening and testing, particularly amniocentesis. This paper aims to build on her work by exploring some of the issues raised by women offered innovative first trimester (11-13 weeks gestation) maternal serum and nuchal translucency (NT) screening, which takes place within the context of a detailed ultrasound scan. Second trimester serum screening for Down's syndrome and neural tube defects has a well-established place in antenatal care. Increasingly, however, first trimester NT screening, particularly in combination with maternal serum screening with biochemical markers, is being proposed as an advance, yielding higher detection rates of Down's syndrome at an earlier gestational age (Spencer, Spencer, Power, Dawson, \& Nicolaides, 2003). NT refers to the subcutaneous space between the skin and the cervical spine of the fetus, and an increased NT is associated with an increased risk of aneuploidy, particularly trisomies 21 (Down's syndrome), 18 (Edward's syndrome) and 13 (Pateau's syndrome). An increased NT is also associated with major defects of the heart and a wide range of skeletal dysplasias and genetic syndromes (Nicolaides, Heath, \& Liao, 2000).

There is limited research on the experiences of women offered this innovative technology. Medical research has tended to concentrate on improving the specificity and sensitivity of NT screening, with 'adequate training and rigorous audit' being recommended (Nicolaides et al., 2000). Other research has focused on the experiences of practitioners offering first trimester screening, which included dilemmas about how much information to give women; how to enable women to make an informed choice in a context where lack of time and increasing routinisation mitigated against this; and specific ethical dilemmas relating to NT screening, such as the right of women to "know everything', including details of soft markers of unknown significance, versus potentially increasing their anxiety (Williams, Alderson, \& Farsides, 2002a). However, women's experiences of first trimester screening, and NT screening as a specific screen for Down's syndrome and other chromosomal disorders remains under explored (Green, 2003), and this paper begins to address that issue.

In the UK, there has traditionally been a wide variation regarding both who should be offered screening for Down's syndrome, and the method to be used. However, in 2003, 
the offer of screening for fetal anomalies, particularly Down's syndrome, became a routine part of antenatal care for the first time, to be offered to all pregnant women. Guidelines also stated that, 'pregnant women should be offered screening for Down's syndrome with a policy that provides a minimum detection rate of $70 \%$ with a falsepositive rate no greater than 5\%' (NICE, 2003, p. 72), indicating a potential move to first trimester screening technologies which achieve this greater level of accuracy. These are very significant shifts in policy, and our research project provided the opportunity to explore the possible consequences of such shifts, prior to widespread implementation. One aspect we wished to explore was whether, or to what extent, women in our innovative setting acted as 'moral pioneers', as 'moral philosophers of the private' (Rapp, 1999). It could be argued that the term 'pioneer', defined in the Oxford Dictionary as 'original investigator of something', may no longer be appropriate, as antenatal screening is now such an established part of pregnancy care. However, antenatal screening is constantly evolving, as are the technological advances which impact on it, including possible developments in fetal medicine and shifting notions of fetal viability, patienthood and personhood.

Returning to the work of Rapp (1999), she argues that:

...the construction and routinization of this technology is turning the women to whom it is offered into moral pioneers: situated on a research frontier of the expanding capacity for prenatal genetic diagnosis, they are forced to judge the quality of their own fetuses, making concrete and embodied decisions about the standards for entry into the human community ( $p .3)$...the women I was interviewing were enunciating a nuanced ethics of reproductive control' ( $p .307$ ).

However, the women interviewed by Rapp represented a selected, high-risk population who, for a variety of reasons, might be more likely to address these ethical dilemmas. Firstly in order to achieve a definitive diagnosis, most of the women Rapp interviewed had chosen to undergo invasive diagnostic testing by amniocentesis, which in itself has a quoted miscarriage rate of about $1 \%$, and is performed at about 16-18 weeks gestation. The majority of women were being tested because of their 'advanced maternal age', which is linked to a higher incidence of having a baby with Down's syndrome. These women had almost always seen a genetic counsellor prior to making a decision, so they had generally had the opportunity to reflect on these issues in a formal health setting. In contrast, the women in our innovative site were making decisions about accepting first trimester screening, a universally offered, earlier, non-invasive screening test in the context of what might be perceived as a 'routine' 12-week scan. This was in the knowledge that the most likely outcome would be a 'low-risk' result, and that the result obtained would not give a definitive diagnosis, merely a risk estimate. In view of these significant differences between the technologies and contexts, we questioned whether the women in our innovative site would, like the women in Rapp's study, be acting as 'moral pioneers', or whether the differences might mean that ethical dilemmas would not be particularly considered by women at this much earlier stage. This is an important question, particularly in view of the UK policy shifts highlighted above which mean that every pregnant woman will be confronted with antenatal screening choices, probably within the context of first trimester screening.

Methods 
The paper reports on one aspect of a multi-method study which explored and compared the risks and benefits of innovative and established models of antenatal screening primarily for Down's syndrome, as defined and communicated by pregnant women, practitioners and policy makers. The study took place in two sites, one offering first, and the other 2 nd trimester screening.

This article focuses specifically on the experiences of those women undergoing first trimester screening at what was at the time the only National Health Service (NHS) onestop clinic in England providing first trimester NT screening in combination with maternal serum screening, with results provided within $1 \mathrm{~h}$. Uptake at this innovative site was very high, with $97.5 \%$ of women accepting screening, compared to around $60 \%$ nationally accepting 2nd trimester screening. In a 3-year retrospective review of screening performance at this district general hospital site (Spencer et al., 2003), on a population of 12,339 women, women with an estimated risk of one in 300 or higher of carrying a fetus with trisomy 21,18 or 13 were offered invasive diagnostic testing. This could usually be arranged for the following day, if requested by women. The uptake of invasive testing in the increased risk group was reported as $77 \%$; the rate of detection of trisomy 21 was $92 \%$ ( 23 of 25 ); of trisomy 13 or 18, $100 \%$ (all 15); and for all anomalies, $96 \%$ ( 49 of 51 ). The false positive rate was $5.2 \%$. This new technology thus provides earlier, faster, more accurate screening, and is conflated with other antenatal procedures such as the dating scan and the 'booking bloods' that take place when women generally first attend hospital at about 11 weeks. As part of our study, at this site 28 semi-structured in depth interviews were carried out with a purposive sample of 15 women, at critical junctures of different screening pathways (three pre-screening; 14 post-screening; 11 post-natal). The study design thus incorporated a longitudinal perspective on changes that occur over the duration of pregnancy and childbirth.

This paper is based on the 14 post-screening interviews which were completed when women were between 12 and 18 weeks pregnant (average 14.8 weeks). To protect confidentiality and anonymity, each participant is identified by a number 1 , indicating site 1 , followed by her own unique number. Of the 14 women, nine had accepted both the ultrasound scan incorporating NT screening and maternal serum screening, screening 'low risk' $(1.3,1.4,1.5,1.6,1.7,1.8,1.9,1.15,1.16)$; two women had screened 'high risk': one for trisomy 21, who opted for no diagnostic testing (1.2); one for trisomy $13 / 18$, who opted for diagnostic testing, with a negative result (1.1); two had refused maternal serum screening, but had accepted the ultrasound scan (1.12, 1.13); one refused both the scan and maternal serum screening (1.14).

Interviews lasted between 1 and $2 \mathrm{~h}$, took place at the woman's home, and with permission, were taped and transcribed. The interviews were conducted as 'guided conversations' (Lofland \& Lofland, 1984), in order to encourage women to give their own accounts and meanings. Open ended questions and an informal interview schedule were used, in order to encourage women to speak in their own words about their experiences and opinions. Transcripts were analysed by content for emergent themes (Weber, 1990) which were then coded (Strauss \& Corbin, 1990). Codes were compared for similarities and differences across the groups, eventually leading to broader themes which made up the overall theoretical framework (Charmaz, 1983). The research team met frequently to discuss the data and analysis and to incorporate different perspectives, in order to add to the richness and validity of the analysis.

Themes 
This paper firstly explores the significance and place of the scan in first trimester screening and some of the potential dilemmas for women that can result from this. It then examines the ways in which this group of women made their decisions about screening, in particular, their moral and ethical choices. The discussion then incorporates findings from both sections to explore the work of women as 'moral pioneers' (Rapp, 1999).

\section{Ultrasound scans in first trimester screening}

To a great extent, ultrasound scans are now accepted as a routine part of pregnancy care. They may be eagerly anticipated by women and their partners, offering the first chance to 'see' the baby. With the exception of one woman (1.14), all the women in our innovative site had a scan, and all described it in very positive terms:

1.4 To see that little baby, oh I don't know, it's fantastic...it was lovely, brilliant, it's so nice.

1.5 The scan was the most fantastic thing...it was just wonderful.

1.6 I've seen it on the telly but when it's happening to you, I think because I really do want this baby, it's kind of like, 'Wow', and just looking at the screen, and it's like, nobody could ever tell me how I would feel to have that sort of-I don't know, it's like in absolute awe of something, it's really quite sort of, 'Wow, that's MY baby, MY baby', you know.

1.7 Well I was delighted really. I'm not one to show my emotions that much, but I was, I really was excited about seeing the baby and I just prayed that everything was OK... I think it brings it all into terms, so you think, 'it's real, it's happening, I'm carrying another life'. I couldn't wait to go into work, 'I've heard the baby's heartbeat', I was telling everyone...

They also described the significance of the scan for their partners:

$1.12 \mathrm{He}$ [partner] was over the moon, absolutely over the moon, yes. He's driving round now with one of these [scan photo] in his car...and he kisses my stomach every day, and the days I don't see him he says, 'kiss the baby for me'.

1.5 My husband was sitting there...he was grinning and going, 'ah, it's moving, it's waving its arms'...then it started moving, my husband said it was punching its little arms... I think maybe it might make men feel a bit more differently about it. I think it made it a lot more real for my husband, because he's started talking a lot more about the baby now.

The recognition of the powerful effects of ultrasound scans is not new, and it has long being argued that fetal ultrasound images can have a number of profound implications. For example, they can potentially change the meanings of pregnancy for women (Mitchell, 2001; Rothman, 1989; Taylor, 1998); men (Draper, 2002; McCreight, 2004) and health practitioners (Williams, Alderson, \& Farsides, 2001; Williams et al., 2002a); and it is argued that they can mark a change in the social status of the fetus, to that of 'social child' (Draper, 2002; Williams, 2003). As Mitchell and Georges (1998, p. 120) state: 
Pregnant women expect that they will "meet their baby" on the ultrasound screen, and are encouraged by experts to see in the image digitalized evidence of a gendered, conscious and sentient fetal actor communicating its demands and needs.

More generally, there are a number of inter-related developments which have led to this move towards viewing the fetus as meriting a place on the social stage, including the recent ways in which, 'the use of fetal images, visualization techniques and medical procedures have placed "life before birth" in front of our cultural eyes' (Michaels \& Morgan, 1999, p. 6). However, it is also argued that recent technological advances which produce much higher-quality fetal ultrasound images, thereby further facilitating more complex fetal diagnoses and treatment, may be further shifting perceptions of the fetus towards that of patienthood and potentially, to personhood (Williams, 2005). In our study, women who had had a previous pregnancy were particularly aware of the increased clarity of scans:

1.9 The scan was great, the scan was clearer than before [last pregnancy]. That's way improved...you could actually see the outline of the nose and everything, whereas we couldn't the first time.

In the context of first trimester screening where the ultrasound scan is being used as a very specific screening tool, women recognised that this technological improvement could potentially cause problems if a possible anomaly was identified:

1.8 Yes, the scan was lovely, and I couldn't believe the difference between this time and last time. Then I was having [child's name], and they'd say, 'There's the leg, and there's this', and it just looked like blobs on the screen. This time, it looked like a little baby. But I did think afterwards, when you do all the waiting around afterwards for your results and everything, I just thought, 'my God, if something was wrong after you'd seen it there on the screen'-it made it so real. I just felt, 'Oh, it must be absolutely horrendous if something was wrong'.

1.9 Obviously I know they can't do these tests without showing you the scan, but it's easy to sit at home and say, 'right, if they say this, we will obviously terminate the pregnancy', but when you see that baby on the screen, you don't care what it's got wrong with it, you just see that it's there and you know it's inside you...it must be a horrible decision once you've actually seen that this is the baby inside you, to suddenly say, 'no, I don't want to carry on with it'. I think that must be quite a heartbreaking decision to make.

The recognition of such potential difficulties in relation to ultrasound scans is not new. Rapp (1999) also described the dilemmas that the intertwined technologies of scans and amniocentesis could have for the women in her study undergoing 2nd trimester testing. However, it should again be emphasised that there is no comparison between the clarity of scans produced even 5 years ago, and now. Drawing on Rothman's (1989) work, Taylor (1998, p. 24) argues that:

...pregnancy is constructed more and more as a "tentative" relationship, and the fetus as a "commodity", at the same time and through the same means that pregnancy is also constructed more and more as an absolute and unconditional relationship, and the fetus as a "person" from its earliest stages'. 
In our sample, only one woman underwent diagnostic testing following a high-risk result, but the following quote helps illustrate her thoughts whilst testing was taking place using ultrasound visualisation:

1.1 She [doctor] said, 'It's [the fetus] fine, look, it's running about'...but I was just thinking, 'that baby is probably deformed and it's inside me, and ooooh' [scared noise]... And she just said, "keep looking at the screen, just concentrate on the screen', but I just looked away...because I didn't want to get attached to this thing that was moving, you know [tearful].

It is hard to speculate what the longer-term effects of such an experience might be. A number of studies have found that many women continue to experience residual anxiety following a problematic screening result, even when diagnostic testing showed a 'normal' result (e.g., Baillie, Smith, Hewison, \& Mason, 2000; Tymstra, 1986; Weinans et al., 2000). However, what is clear is that in the UK, with its recent policy move towards the routine offer of screening for fetal anomalies, particularly Down's syndrome, and the potential move to first trimester screening, with its generally higher uptake rate, many more women will be confronting these ethical dilemmas. To conclude this section, it appears that the part played by the ultrasound scan in first trimester screening, particularly in relation to the higher-quality images produced, has the potential to throw up new and novel ethical dilemmas for pregnant women, which are only just beginning to be explored.

Women's decision-making around first trimester screening

Amongst the criticisms levelled at antenatal screening in general, is the concern that women may not be aware that they are in fact, consenting to an optional test, or that they may not understand what the potential results might signify. It is also recognised that women are more likely to accept tests when they are absorbed within the context of non-controversial routine antenatal care (Press \& Browner, 1997). These criticisms are of particular concern in relation to first trimester screening, which is set within the context of a scan that women and their partners usually look forward to, leading Green (2003, p. 63) to argue that:

one of the keys to women's enthusiasm for scans [is that] they do not view them as a threat that might give them bad news (like amniocentesis) but as a benign procedure which allows them to see their baby and confirm that it is healthy. Their assumption that the procedure is benign, is, of course, encouraged by the fact that scans are routine and given to everyone.

In this section, factors such as women's specific knowledge about the screening process and the conditions screened for will not be explored. Rather, the focus is on the extent to which women in this innovative site recognised that scans might not necessarily be 'benign', and that in contrast, scans might give them problematic information requiring moral judgements to be made. One of the few previous studies exploring women's decision-making in relation to first trimester NT screening found that although midwives did emphasise the purpose of NT screening and the status of the results, women themselves often framed their decision to have NT screening in terms of it being a formality, or of presuming that all was well (Pilnick, Fraser, \& James, 2004). A small number of the women we interviewed did appear to have viewed first trimester screening in these ways, thus bypassing moral work, at least initially: 
1.1 The scan appointment wasn't about screening, it was just something I went along to, to have the scan and see the baby. Screening wasn't important for me until I got the results.

1.4 There's no reason to say no...we just read through it and we said, 'no harm'..see, I think we're not experts in this baby thing anyway, so it's like whatever they offer, we would just take it, as long as it's not harming me or the baby, that's fine.

However, the majority of women interviewed did report having thought carefully about their own moral values and beliefs in relation to aspects of the screening process, prior to making their decision. One of the most striking features about the interviews is the emphasis women placed on the decision-making being a very individual, private process. This is not to say that women did not discuss it with others, or seek advice from other sources, but they recognised that ultimately the responsibility was theirs. So although, for example, partners were often included in the process, the final decision-and responsibility-lay with women:

1.6 He (partner) just sort of leaves me to it..he would just leave it that it would be my choice to have the screening done...but I think he would find it very hard if we had a baby which [had a disability].

It was apparent that many women had tried to think through the possibility of a "highrisk' result, and what they might do:

1.6 For me, having looked after a lot of children with special needs and having a reasonable understanding of the impact without obviously being in that situation myself, of the implications for the whole family, I personally would not choose to have a child if they were to have Down's syndrome, or any sort of defect whichit's not that I want a perfect baby, and if I didn't get a perfect baby-I've seen complications at birth, so what you're given is what you've got sort of thing. I don't know whether it's wrong to think like that, but I would rather know...but having said that, I don't know what I would do if somebody said, 'you've got something wrong with your baby'. I would have to have a long, hard think about what the condition was, as to how severely the baby's quality of life was affected, as to whether I chose to carry on the pregnancy or to terminate.

1.8 This is why I panic, because where do you draw the line, because people get things wrong with them at different severities don't they? And I think if you've got a baby, you love it-whatever it's got wrong with it, you still love it and protect it, don't you? I know people who would say, 'no, that baby's got something wrong with it, I'm not having it'.. but that's why the test would be hard for me, because I wouldn't be straightaway, 'oh, if there's something wrong, I'm not having it'.

1.7 I think every woman's concerned whether everything's forming as it should...and I know that Down's children can lead normal lives and everything else, it's just a matter of treatment and their life expectancy isn't usually that great, I think it's about 40 or something like that-I mean, life just begins then... I think, it's an ethical reason really isn't it, whether it's right to terminate a life just because you feel it would serve no purpose only having a limited life span. I don't know, it's a hard question I think. 
These quotes echo a longstanding body of work which shows how women are culturally positioned to view their reproductive capacities and decisions as a private dimension of public life (e.g., Rothman, 1989; Throsby, 2004). More specifically in relation to responsibility, Rapp (1999, p. 308/9) states:

Women judge the acceptability of specific fetuses for their entry into their communities because there are so few limits on women's responsibility for the quality of life that the child would have...the very fact of imagining (and more rarely, enacting) a limit comes with the territory on which gendered responsibilities encounter reproductive technologies'.

One key reason that women opted for first trimester screening was so that they could have an earlier termination of pregnancy if an anomaly was found. For some, this was clearly linked to ethical dilemmas relating to shifting knowledge about fetal viability:

1.6 If things were going to be wrong, I would rather know, I'd rather they were to happen now rather than waiting until 23 weeks, and you've got a fairly viable pregnancy if the baby was to be born then. They'd probably end up in intensive care for a little while, but the fact is that it's more of a baby then, and therefore if something was wrong and you did decide to terminate, you'd have to go through the birth. That would be the most empty experience to me that I think there could be.

1.1 I would much rather know at this early stage...because I couldn't imagine carrying a baby for 20 weeks, getting bigger, or 30 weeks and then miscarry. That would be so-especially after 24 weeks, when life is viable. Or even having a stillbirth.

As was seen in the first section in terms of the increased clarity of scans, these quotes illustrate the impact of related technological advances, here the shifting understandings of fetal viability, on uptake of first trimester screening. Others could not contemplate the procedure that a late termination of pregnancy can necessitate:

1.5 I mean, at 16 weeks you're starting to really notice that there's a baby there, and if you're going to do anything about it, you don't have much time, because after 24 weeks, you absolutely have to deliver the baby, and I would HATE to do that...there's no way I could choose to terminate a pregnancy at that stage...jt would be easier if I could just go to the hospital and have a little D and C [surgical termination] and that's it, but if you actually have to go through the whole process of actually giving birth to a child, no, I couldn't possible terminate.

Recognising that this is a highly charged moral area, some women also preferred the opportunity of being able to keep the potential decision to terminate their pregnancy a private one:

$1.16 \ldots$ I suppose the biggest thing for me about the scan because it's so early, it would mean if you was gonna make a decision like that no one would know unless you wanted them to know, whereas at 18 to 20 weeks everybody would know whatever you decided to tell them, and so as hard as it might be it would make it easier for you. 
The few women who decided against screening had also thought carefully through the implications of an adverse screening result in relation to their moral beliefs and values:

1.14 And the assumption [of screening] that I would select, based on the baby, was, you know, it's obviously helpful for some people, but I found it morally not so, we both did. When we first talked about having a baby, we knew that if it was a Down's baby, then it's a Down's baby, you know. No one wanders round hoping for a Down's baby...but to me, to us, it was about taking on this sort of vulnerability of human life, and morally...

1.12 I just think that pregnancy and having a baby is such a wonderful gift, that no one has the right to either end a pregnancy, or-not that I'm saying, you know, I don't judge other people, it's just that I couldn't do it.

Although this woman was clear that she would not consider an abortion and had initially refused NT screening, she did agree to it when she was told that it could potentially detect cardiac anomalies:

1.12...because obviously if the baby had cardiac problems and if there was something they could do about that, something positive they could do, then I would be happy for that, you know... I mean, you hear of babies being operated on their hearts before they're even born and things like that, I mean, obviously I would do anything to improve it, if an improvement could be made. So that's why I agreed to have the scan done.

This woman's experience clearly illustrates another possible consequence of the routine offer of first trimester screening to all pregnant women, namely, the potential 'dragnet' effect of prenatal screening described by Alderson, Williams, and Farsides (2004, p. 75):

Intended to benefit everyone equally, the dragnet (Illich, 1976) treats all pregnancies as potentially pathological and needy, drawing pregnant women into anxious dependence on expert medical risk management... Aims to promote universal access to screening as beneficial and necessary, conflict with respect for women's informal refusal as a rational choice.

It also shows again the impact of the expectations of sometimes unproven technological advances, in this case, fetal cardiac surgery, on women's screening decisions (Kitzinger $\&$ Williams, in press).

To conclude this section, in contrast to other findings, it seems that many of the women interviewed in our innovative site were aware that first trimester screening had the potential to identify fetal anomalies. They reported having thought carefully about their own moral values and beliefs in relation to aspects of the screening process, prior to making their decision. This is also an area of medicine where, rather than being strategically introduced, antenatal screening programmes tend to 'creep in' (Bricker et al., 2000, p. 82), often leading to a subtle but rapid process of incorporation, routinisation and consequent consumer demand (Williams, Alderson, \& Farsides, 2002b). For reasons such as those, pregnant women negotiating antenatal screening appear to be making decisions in ever shifting settings. Finally, it should be emphasised that thinking through their moral beliefs and values should not necessarily be equated with women having accurate information about, for example, the conditions being screened 
for (Sandall et al., submitted), or the screening process itself (Heyman, Lewando-Hundt, Sandall, Spencer, \& Williams, submitted).

Discussion and conclusions

Firstly, although the focus of this paper has been on the experiences of individual women, it should of course be stated that:

A range of material, commercial, professional and bureaucratic actors shape the design and implementation of these [antenatal screening] technologies, from the broad aims of the programme of which they are a part, to the fine details of which tests to use, and error margins to accept (Kerr, 2004, p. 82).

In addition, although research has shown pregnant women can be active agents, rather than merely passive victims (Weiss, 1995), there is also a simultaneous recognition that women's individual reproductive choices are made within the context of familial, social, cultural and economic constraints (Henry, 2003).

It is acknowledged that the paper has explored only a small number of women's experiences of combined ultrasound, NT and serum screening in one unique setting and as such, findings must be tentative. However, in the antenatal setting, where new screening programmes can be rapidly incorporated, the experiences of these women does allow us to speculate on some of the possible implications of this IMT, prior to its potentially more widespread use. In this paper, we have particularly focused on the part played by ultrasound scans and the moral decision-making of women, to explore women's role as 'moral pioneers'.

In this site, almost the entire population of pregnant women opted for combined first trimester screening. However, the possible impact of this screening programme on the meanings of pregnancy for women is difficult to determine. It could, for example, be argued that this screening innovation, which has the potential to become highly routinised, may serve to decisively consolidate the biomedical model of pregnancy, by foregrounding the possibility of fetal anomalies so early on in pregnancy. Others might argue that earlier, more accurate first trimester screening conveys advantages for women, particularly those who would wish to terminate an affected pregnancy (Spencer \& Aitken, 2004). What does seem clear is that in the current UK policy climate, within which every woman must be offered the option of antenatal screening, innovative first trimester screening technologies firmly maintain the emphasis on the individualised risk model of pregnancy, whereby pregnant women themselves are enlisted in, and become responsible for 'their own government' (Harris, Connor, Bisits, \& Higginbotham, 2004, p. 31). As others have noted, this responsibility has particular consequences in the antenatal setting:

When professionals give clients choices they also give them responsibilities for these choices, which can be burdens in their own right. In many ways, this version of choice privatizes responsibilities for preventing disability, or, should the test be declined, facing up to the future of living with a disabled child (Kerr, 2004, p. 82).

It seems likely that, as with other innovations in reproductive medicine, first trimester screening gives rise to both benefits and dilemmas. As Casper (1998, p. 220) states: 
Reproductive medicine both heals and harms women; it both produces and destroys fetuses; it is both palliative and iatrogenic; it both opens and closes reproductive possibilities; it is both a consumer choice and a form of social control; and it both shapes cultural meanings and it is a product of culture.

Our findings also support Brown and Webster (2004), who state that many aspects of current research on new reproductive technologies (NRTs) echo earlier work, particularly the continuing ambivalence that NRTs can create for women. However, they argue that there are always new processes at work at the 'intermediation of society and technologies', necessitating further research. Similarly, in the area of antenatal screening, each technological advance, often seemingly minor in itself, may serve to shift the experiences of women in subtle but significant ways. These are difficult and complex aspects to tease out when exploring the experiences of women, particularly in our innovative site which simultaneously introduced a number of changes under the rubric of first trimester screening, with the potential for subtle and cumulative effects. Although many of these factors have been addressed by previous research, we argue that it is the novel combination of cumulative factors first trimester screening incorporates, plus related external developments, that necessitates pregnant women continuing to act as 'moral pioneers' in this setting.

For example, with $97.5 \%$ of women accepting the offer of screening, the context has very much shifted to that of routine screening, which may in turn enhance the 'dragnet' effect of the screening programme. As was seen, this 'dragnet' effect may be further enhanced by women's perceptions of technological advances, including developments in fetal medicine and surgery, which in turn relate to shifting notions of fetal viability, patienthood and personhood (Williams, in press). One reason for the high uptake of screening was that it was performed within the context of a scan. However, we argue that the recently increased clarity of ultrasound scans, when the scan itself is being used as a specific screening tool, can also lead to new moral dilemmas. For example, if women wish to construct a 'tentative' relationship with their fetus under particular circumstances, might this task-and relationship-be qualitatively different with much higher-quality scans? In addition, in this site, combined serum and scan results were available within $1 \mathrm{~h}$ and diagnostic testing could be arranged within 24-48 h. Furthermore, if women wanted a surgical TOP as opposed to a feticide followed by labour, the decision had to be made fairly rapidly. Consequently, the state of 'tentativeness' could arise suddenly, in contrast to more established screening methods, potentially leading to new moral dilemmas.

More generally, Getz and Kirkengen (2003, p. 2054) argue that the implementation of ever-advancing biotechnology in this area where medicine, social values and culturally determined meaning are so closely intertwined, has resulted in pregnant women being confronted with 'unprecedented ethical dilemmas' and responsibilities. Some of the interrelated factors which may help make such decisions unprecedented were alluded to by the women in our study, including the uniqueness of the maternal-fetal relationship, decision-making on what is often complicated risk and probability based information, and decision-making in a highly charged moral area. It would therefore seem that whatever other implications they may have, innovative first trimester screening technologies will continue the tradition of pregnant women acting as 'moral pioneers' in increasingly complex settings, and at a much earlier stage of pregnancy than previous screening policies necessitated. 
Acknowledgements

We are very grateful to everyone who participated in this research, and to the ESRC/MRC Innovative Health Technologies Programme for funding the project (grant no: L218252042). We also acknowledge the contribution of Laura Pitson and Maria Tsouroufli, researchers on the project. CW acknowledges the support of The Wellcome Trust Biomedical Ethics Programme in funding her postdoctoral fellowship, which enabled her to work on this project.

References

Alderson, P., Williams, C. and Farsides, B. (2004). Practitioners' views about equity within prenatal screening services, Sociology 38, pp. 61-80.

Baillie, C., Smith, J., Hewison, J. and Mason, G. (2000). Ultrasound screening for fetal abnormality: Women's reactions to false positive results, British Journal of Health Psychology 5, pp. 377-394.

Bricker, L., Garcia, J., Henderson, J., Mugford, M., Neilson, J., Roberts, T. et al. (2000). Ultrasound screening in pregnancy: A systematic review of the clinical effectiveness, cost effectiveness and women's views, Health Technology Assess 4, p. 16.

Brown, N. and Webster, A. (2004). New medical technologies and society, Polity, Cambridge.

Casper, M. (1998). The making of the unborn patient, Rutgers University Press, New Brunswick.

Charmaz, K. (1983). The grounded theory method: An explication and interpretation. In: R. Emerson, Editor, Contemporary field research: A collection of readings, Waveland Press, Prospect Heights, III, pp. 109-126.

Draper, J. (2002). 'It was a real good show': The ultrasound scan, fathers and the power of visual knowledge, Sociology of Health and IIlness 24, pp. 771-795.

Fox, R. (2000). Medical uncertainty revisited. In: C. Bird, P. Conrad and A. Freemont, Editors, Handbook of medical sociology (5th ed.), Prentice-Hall, Englewood Cliffs, NJ .

Getz, L. and Kirkengen, A. (2003). Ultrasound screening in pregnancy: Advancing technology, soft markers for fetal chromosomal aberrations, and unacknowledged ethical dilemmas, Social Science \& Medicine 56, pp. 2045-2057.

Green, J. (2003). Women's experiences of prenatal screening and diagnosis. In: L. Abramsky and J. Chapple, Editors, Prenatal diagnosis: The human side (2nd ed.), Nelson Thornes, Cheltenham, pp. 56-69.

Harris, G., Connor, L., Bisits, A. and Higginbotham, N. (2004). "Seeing the baby": Pleasures and dilemmas of ultrasound technologies for primiparous Australian women, Medical Anthropology Quarterly 18, pp. 23-47.

Henry, M. (2003). Investing in mothering. In: S. Williams, L. Birke and G. Bendelow, Editors, Debating biology, Routledge, London, pp. 185-197. 
Heyman, B., Lewando-Hundt, G., Sandall, J., Spencer, K. and Williams, C. (submitted). On being at higher risk: A qualitative study of 'innovative' and 'standard' prenatal screening for chromosomal anomalies. Health, Risk and Society.

Illich, I. (1976). Limits to medicine, McClelland and Stewart, London.

Kerr, A. (2004). Genetics and society: A sociology of disease, Routledge, London.

Kitzinger, J. and Williams, C. (in press). Forecasting science future: Legitimising hope and calming fears in the embryo stem cell debate. Social Science $\&$ Medicine.

Lofland, J. and Lofland, L. (1984). Analyzing social settings: A guide to qualitative observation and analysis, Wadsworth, Belmont, CA.

McCreight, B. (2004). A grief ignored: Narratives of pregnancy loss from a male perspective, Sociology of Health and IIIness 26, pp. 326-350.

Michaels, M. and Morgan, L. (1999). Introduction: The fetal imperative. In: L. Morgan and M. Michaels, Editors, Fetal subjects, feminist positions, University of Pennsylvania Press, Philadelphia, pp. 1-10.

Mitchell, L. (2001). Baby's first picture: Ultrasound and the politics of fetal subjects, University of Toronto Press, Toronto.

Mitchell, L. and Georges, E. (1998). Baby's first picture: The cyborg fetus of ultrasound imaging. In: R. Davis-Floyd and J. Dumit, Editors, Cyborg babies: From techno-sex to techno-tots, Routledge, London, pp. 105-124.

NICE. (2003). Antenatal care: Routine care for the healthy, pregnant woman. London: National Collaborating Centre for Women's and Children's Health, Commissioned by the National Institute for Clinical Excellence.

Nicolaides, K., Heath, V. and Liao, A. (2000). The 11-14 week scan, Ballieres Best Practice and Research in Clinical Obstetrics and Gynaecology 14, pp. 581-594.

Pilnick, A., Fraser, D. and James, D. (2004). Presenting and discussing nuchal translucency screening for fetal abnormality in the UK, Midwifery 20, pp. 82-93.

Press, N. and Browner, C. (1997). Why women say yes to prenatal diagnosis, Social Science \& Medicine 45, pp. 979-989.

Rapp, R. (1999). Testing women, testing the fetus, Routledge, London.

Rothman, B. (1989). Recreating motherhood: Ideology and technology in a patriarchal society, Norton, New York.

Sandall, J., Pitson, L., Williams, C., Lewando-Hundt, G., Spencer, K. and Heyman, B. (submitted). 'Going with the flow': First trimester antenatal screening for Down's syndrome in an innovative one-stop clinic. Routinisation and constraints on informed decision making. British J ournal of Obstetrics and Gynaecology.

Spencer, K. and Aitken, A. (2004). Factors affecting women's preference for type of prenatal screening test for chromosomal anomalies, Ultrasound in Obstetrics \& Gynecology 24, pp. 735-739. 
Spencer, K., Spencer, C., Power, M., Dawson, C. and Nicolaides, K. (2003). Screening for chromosomal abnormalities in the first trimester using ultrasound and maternal serum biochemistry in a one-stop clinic: A review of three years prospective experience, BJ OG: An International Journal of Obstetrics and Gynaecology 110, pp. 1-6.

Strauss, A. and Corbin, J. (1990). Basics of qualitative research, Sage, London.

Taylor, J. (1998). Image of contradiction: Obstetrical ultrasound in American culture. In: S. Franklin and H. Ragone, Editors, Reproducing reproduction, University of Pennsylvania Press, Philadelphia, pp. 15-45.

Throsby, K. (2004). When IVF fails: Feminism, infertility and the negotiation of normality, Palgrave Macmillan, Basingstoke.

Tymstra, T. (1986). False positive results in screening tests: Experiences of parents of children screened for congenital hypothyroidism, Family Practice 3, pp. 92-96.

Weber, R. (1990). Basic content analysis, Sage, London.

Webster, A. (2002). Innovative health technologies and the social: Redefining health, medicine and the body, Current Sociology 50, pp. 443-457.

Weinans, M., Huijssoon, A., Tymstra, T., Gerrits, M., Beekhuis, J. and Mantingh, A. (2000). How women deal with the results of serum screening for Down syndrome in the second trimester of pregnancy, Prenatal Diagnosis 20, pp. 705-708.

Weiss, G. (1995). Sex-selective abortion: A relational approach, Hypatia 12, pp. 202217.

Williams, C. (2003). The personalization of the fetus, or, 'He looks just like his father!', MIDIRS Midwifery Digest 13, pp. 47-49.

Williams, C. (2005). Framing the fetus in medical work: Rituals and practices, Social Science \& Medicine.

Williams, C. (in press). Dilemmas in fetal medicine: Premature application of a technology or responding to women's choice? Sociology of Health and Illness.

Williams, C., Alderson, P. and Farsides, B. (2001). Conflicting perceptions of the fetus: Person, patient, 'nobody', commodity?, New Genetics and Society 20, pp. 225-238.

Williams, C., Alderson, P. and Farsides, B. (2002). Dilemmas encountered by health practitioners offering nuchal translucency screening: A qualitative case study, Prenatal Diagnosis 22, pp. 216-220.

Williams, C., Alderson, P. and Farsides, B. (2002). Too many choices? Hospital and community staff reflect on the future of prenatal screening, Social Science \& Medicine 55, pp. 743-753. 